\title{
Structured Training to the Patients of Chronic Obstructive Pulmonary Disease Reduces Frequency of Hospital Readmission
}

\author{
Md. Mizanur Rahman ${ }^{1}$, MA Azhar ${ }^{2}$, Anup Kumar Saha ${ }^{3}$, Kamrun Nahar $^{4}$
}

\begin{abstract}
Background: Patient education after treatment of acute exacerbation in patients with chronic obstructive pulmonary disease (COPD) prevents frequent hospital readmission and improve quality of life. Objectives: To observe the impact of providing structured training to patients of COPD on repeated hospital admission. Materials and method: This prospective comparative study was carried out in the inpatient department of Medicine and Pulmonology Unit, Sir Salimullah Medical College and Mitford Hospital, Dhaka, Bangladesh, from January 2010 to June 2011. A total of 144 admitted patients with COPD with an attack of acute exacerbation were included in this study without having any significant or chronic comorbidity. Of the 144 patients, 72 were randomly allocated for receiving structured training (cases; Group-A) and the rest 72 patients did not receive the training (controls; Group-B). Results: The pertinent demographic characteristics, smoking status, and knowledge about different aspects of COPD, and medications used during acute exacerbation of COPD before intervention were almost similar between the groups. Over 30\% of the patients who received structured training needed no hospital admission, 58.3\% needed only one and $11.1 \%$ needed 2 or more admissions, while the other group required two or more admissions during the same period ( $p<0.001)$. The duration of hospital stay was significantly less in case group. Number of $>2$ consultations with physicians was significantly higher in the former group (26.4\% vs. 6.9\%) ( $p=0.002)$, indicating an increased awareness on the part of that group. Conclusion: Structured training to COPD patients significantly reduced hospitalization and hospital stay for an acute exacerbation in this study.

Keywords: Chronic obstructive pulmonary disease; COPD; structured training.
\end{abstract}

Delta Med Col J. Jan 2018;6(1):35 - 44

\section{Introduction}

Chronic obstructive pulmonary disease (COPD) is a preventable and controllable disease with some significant extra pulmonary effects that may contribute to the severity in individual patients. Its pulmonary component is characterized by airflow limitation that is not fully reversible. The airflow limitation is usually progressive and is associated with an abnormal inflammatory response of the lungs to noxious particles or gases, primarily caused by cigarette smoking. Although COPD

1. Associate Professor, Dept. of Medicine, Tairunnessa Memorial Medical College \& Hospital, Gazipur, Bangladesh.

2. Professor of Medicine, Head \& Principal, Green Life Medical College \& Hospital, Dhaka, Bangladesh.

3. Professor, Dept. of Medicine, SSMC \& Mitford Hospital, Dhaka, Bangladesh.

4. Consultant Radiologist \& Sonologist, Popular Diagnostic Center, Mirpur, Bangladesh.

Correspondence: Dr. Md. Mizanur Rahman. e-mail: mnmch14@yahoo.com 
affects the lungs, it also produces significant systemic consequences. ${ }^{1}$

Chronic obstructive pulmonary disease (COPD) is currently the fifth leading cause of global mortality and morbidity and a major public health problem in both developed and developing countries. $^{2}$ By the year 2020, COPD is expected to become the third-most common cause of death in the world and fifth-leading cause of disease burden. ${ }^{3}$ Progressive introduction of pharmacologic, non pharmacologic and surgical treatments are therefore, necessary to cope with the deteriorating respiratory function in COPD patients. ${ }^{4}$ Acute exacerbations are the most frequent cause of hospital admission and death among COPD patients. ${ }^{5}$ Frequent exacerbations also reduce the quality of life in patients with COPD. ${ }^{6}$

Acute exacerbation of COPD is defined as an event in the natural course of disease characterized by a change in the patients baseline dyspnoea, cough and or sputum that is beyond normal day-to-day variations, is acute in onset and may warrant a change in regular medication in a patient with underlying COPD. ${ }^{7}$

It represents a major burden for patients and health care system, because acute exacerbations are common reason for hospital admissions severely affecting health related quality of life (HRQL) and prognosis. ${ }^{8}$ Mortality rates during hospitalizations are around $10 \%$ and during the year following a hospitalization may be as high as 40\%. ${ }^{9,10}$ From health care providers' perspective, COPD is a highly resource consuming entity. ${ }^{11}$ More than $50 \%$ of the total cost of COPD is accounted for by services related to exacerbations. For instance, in the UK, they are the most common cause of medical hospital admission, accounting for $15 \bullet 9 \%$ of hospital admissions, at a cost to the National Health System of over $£ 253$ million a year. ${ }^{12} \mathrm{~A}$ recent large-scale study found, a readmission rate of $63 \%$ during a mean follow up of 1 year with physical inactivity amongst the significant predictors for readmissions. ${ }^{13}$ The American College of Physicians and American College of Chest Physicians provided recommendations on the management of acute exacerbations of COPD. However, they did not provide recommendation on how future exacerbations and hospitalizations could be minimized, despite being one of the main goals of COPD management. ${ }^{14}$ One solution that has been adopted in clinical practice is to provide patient education after treatment of acute exacerbation including physical exercise, focusing on self-management strategies and psychological support. The rationale to offer education in patients recently treated for acute exacerbation is to enhance health-related quality of life (HRQL) as in stable COPD patients, ${ }^{15}$ but also to modify factors associated with increased risk for post-exacerbation morbidity and mortality. A recent study showed that exacerbations result in acute muscle deconditioning and weakness. ${ }^{16}$ Hence patients with frequent exacerbations have more pronounced skeletal muscle weakness and more limited six minute walking distance, ${ }^{17}$ which is in turn a risk factor for exacerbations and mortality. ${ }^{18}$

Patients' education regarding physical exercise has the potential to reduce hospital admissions by improving exercise capacity. It is hence surprising and in contrast to the large body of evidence supporting patient education in stable patients, ${ }^{19}$ that the effects of education in patients after acute exacerbation has never been studied systematically.

Education interventions for chronic illness aim to provide patients with the knowledge and skills to deal with limitations imposed by disease. Education programmes for asthma, in particular self-management education, have been shown to be an effective means of improving health outcomes including health care utilization, days lost from work and quality of life. ${ }^{20}$ Education is now a key recommendation in asthma management guidelines. ${ }^{21}$ As asthma is a chronic 
lung condition, the improvements in health outcomes noted in this population following educational activities may also be obtainable in the general COPD population. Several trials have now been conducted assessing the benefits of educational programs for the general COPD population. In patients education programme (PEP), patient education means that patient should understand that COPD is a chronic controllable disease, smoking cessation is the key to COPD control, proper use of medications, inhalers, spacers, nebulisers are mandatory to reduce the rates of exacerbation and readmission, importance of home/outside hospital oxygen use, home use of antibiotics, breathing and also of limited physical exercise. This structured training is implemented in two steps: 1) rapport building with patients and 2) seven-point education using a check-list. ${ }^{22}$

The goal of the study was to observe the impact of structured training to patients of COPD on repeated admission. To see the effect of interventions on study group in reducing the frequency of hospital readmission following an attack of acute exacerbation compared with control group (who are not receiving structured training). To see the changes in awareness of the patients regarding COPD, drug compliance, and finally to evaluate the changes in practice of the patients about COPD.

\section{Materials and method}

This prospective observational comparative study was carried out during the period from January 2010 to June 2011, in the inpatient department of Medicine and Pulmonology Unit, Sir Salimullah Medical College and Mitford Hospital, Dhaka, Bangladesh. Patients having the diagnosis of COPD admitted in the inpatient department of Medicine, with an attack of acute exacerbation were the study population. Patients with history of asthma, allergic rhinitis or atopy, suspected malignancy, pulmonary embolus or cardiac disease, were excluded. Due permission was obtained from the Ethical Review Committee of concerned authority. Written consent was obtained from each study subject who voluntarily consented to participate in the study. A total of 144 patients were included in the study and were randomly divided into case and control groups as follows: of the 144 patients, 72 were randomly allocated for receiving structured training as a measure of pulmonary rehabilitation and were considered as cases (Group-A) and the rest 72 patients did not receive the same training and were termed as controls (Group-B). Method of structured training to COPD patients was based on Bangladesh Lung Health Manual, 2002.22 Data were collected using a structured questionnaire (research instrument) containing all the variables of interest. Pertinent information including patients' particular, demographic and clinical characteristics, patients' baseline knowledge, attitude and practice about COPD were recorded as baseline variables. Outcome variables as change in knowledge and practice and their impact as reduction in acute exacerbation and reduction in the frequency of hospital readmission were recorded in the same questionnaire 1 (one) year after intervention. Statistical analysis was performed using SPSS (SPSS Inc., Chicago, IL, USA), version 11.5. Data were compared between groups using Chi-square $(\chi 2)$ or Fisher's exact test, or student's t-test where applicable. Level of significance was set at 0.05 and $p<0.05$ was considered significant.

\section{Results}

Demographic characteristics of the study subjects show that majority of the patients in both groups were $\geq 60$ years old $(72.2$ vs. $62.5 \%, p=0.213)$ and predominantly male ( 91.7 vs. $73.6 \%, \mathrm{p}=$ $0.004)$, rural residents ( 62.5 vs. $70.8 \%, \mathrm{p}=0.036$ ) and illiterate ( 84.7 vs. $83.3 \%, \mathrm{p}=0.820$ ) (Table I). 
Table I: Comparison of age between groups

\begin{tabular}{lccc}
\hline Baseline variables & \multicolumn{2}{c}{ Study subjects } & p-value \\
Group-A & $\begin{array}{c}\text { Group-B } \\
\text { (n=72) }\end{array}$ & \\
\hline Age (in years) & & & \\
$<60$ & $20(27.8)$ & $27(37.5)$ & 0.213 \\
$\geq 60$ & $52(72.2)$ & $45(62.5)$ & \\
$\quad$ Mean \pm SD & $62.1 \pm 10.8$ & $62.2 \pm 9.8$ & \\
Sex & & & 0.004 \\
$\quad$ Male & $66(91.7)$ & $53(73.6)$ & \\
Female & $6(8.3)$ & $19(26.4)$ & 0.036 \\
Residence & & & \\
$\quad$ Urban area & $27(37.5)$ & $17(23.6)$ & \\
$\quad$ Rural area & $45(62.5)$ & $51(70.8)$ & 0.820 \\
$\quad$ Slum dweller & $0(0.0)$ & $4(5.6)$ & \\
Educational status & & & \\
Illiterate & $61(84.7)$ & $60(83.3)$ & \\
Primary & $11(15.3)$ & $12(16.7)$ & \\
\hline
\end{tabular}

Figures in the parenthesis denote corresponding percentage. Chi Square $\left.x^{2}\right)$ test was employed to analyze the data

Table II presents the detailed smoking history of the patients. More than $40 \%$ of Group-A and $34.7 \%$ of Group-B were current smoker. The proportion of past smokers in Group-A and Group-B were $55.6 \%$ and $63.9 \%$ respectively. Very few were non-smokers. The smoking habit was almost identical between the groups $(\mathrm{p}=$ 0.547). Duration of smoking was fairly comparable between groups $(\mathrm{p}=0.534)$ and average number of sticks smoked per day was 20 in either group $(\mathrm{p}=0.138)$.

Table II: Comparison of smoking habit history between groups

\begin{tabular}{|c|c|c|c|}
\hline \multirow[t]{2}{*}{ Smoking History } & \multicolumn{2}{|c|}{ Study subjects } & \multirow[t]{2}{*}{ p-value } \\
\hline & $\begin{array}{c}\begin{array}{c}\text { Group-A } \\
(n=72)\end{array} \\
\end{array}$ & $\begin{array}{c}\text { Group-B } \\
(\mathrm{n}=72)\end{array}$ & \\
\hline \multicolumn{4}{|l|}{ "Smoking habit } \\
\hline Current smoker & $30(41.7)$ & $25(34.7)$ & \\
\hline Past smoker & $40(55.6)$ & $46(63.9)$ & 0.547 \\
\hline Non smoker & $2(2.8)$ & $1(1.4)$ & \\
\hline${ }^{\#}$ Duration of smoking (in years) & $34.5 \pm 9.2$ & $33.6 \pm 5.8$ & $0.534^{\#}$ \\
\hline${ }^{\#}$ Number of sticks smoked/day & $19.6 \pm 4.4$ & $20.5 \pm 2.4$ & $0.138^{\#}$ \\
\hline
\end{tabular}

\section{Exposure to biomass fuel smoke}

Figure 1 shows that $2.8 \%$ of Group-A and $1.4 \%$ of Group-B had exposure to smoke emitted from burning of biomass fuel.

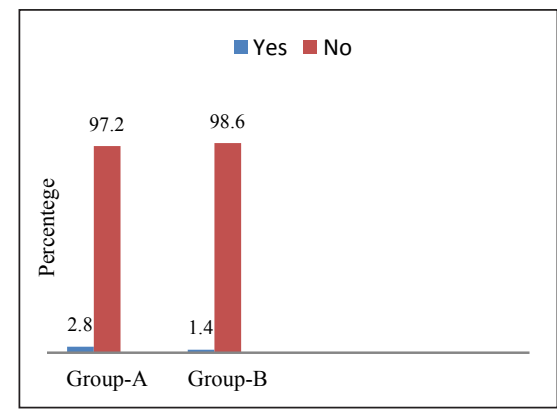

Fig. 1: Distribution of patients by exposure to biomass fuel smoke
Assessment of knowledge about COPD shows that all of the respondents in the both groups were of the opinion that COPD was a lung disease characterized by cough, sputum and breathlessness. More than half of the patients in either group held the view that COPD was chronic progressive lung disease $(\mathrm{p}=0.86)$ and majority linked its relationship with smoking $(\mathrm{p}=0.457)$. However, only $30.6 \%$ of the respondents in Group-A and 25\% in Group-B opined that smoke from other sources also might be associated with COPD ( $\mathrm{p}=0.457)$. Asked about whether COPD had any curative treatment, $70.8 \%$ and $59.7 \%$ told that there was no curative treatment for the disease. In response to an opinion seeking 'whether the respondents agree that doctors cannot cure COPD but can help only to improve symptoms', $45.8 \%$ of Group-A and $58.3 \%$ of Group-B were in favour of the statement with significant intergroup difference $(\mathrm{p}=0.133)$ (Table III).

Table III: Comparison of baseline knowledge about COPD between groups

\begin{tabular}{lccc}
\hline Knowledge about COPD & \multicolumn{2}{c}{ Study subjects } & p-value \\
& $\begin{array}{c}\text { Group-A } \\
(\mathrm{n}=72)\end{array}$ & $\begin{array}{c}\text { Group-B } \\
(\mathrm{n}=72)\end{array}$ & \\
\hline COPD - a lung disease & $72(100.0)$ & $72(100.0)$ & - \\
COPD causes cough, sputum, breathlessness & $72(100.0)$ & $72(100.0)$ & - \\
Smoking cause COPD & $54(75.0)$ & $50(69.4)$ & 0.457 \\
COPD a chronic progressive disease & $38(52.8)$ & $37(51.4)$ & 0.868 \\
Smoke from other sources cause COPD & $22(30.6)$ & $18(25.0)$ & 0.457 \\
COPD have no curative treatment & $51(70.8)$ & $43(59.7)$ & 0.161 \\
Doctor cannot cure CoPD only $\quad$ helps & $33(45.8)$ & $42(58.3)$ & 0.133 \\
improve symptoms & & & \\
\hline $\begin{array}{l}\text { Figures in the parentheses denote corresponding percentage } \\
\text { Chi Square }\left(\chi^{2}\right) \text { Test was employed to analyze the data }\end{array}$ &
\end{tabular}

Almost all the patients in Group-A and Group-B had the knowledge that Improve symptoms sulbutamol should be used for getting relief from COPD. Knowledge about use of aminophyline tablets was also satisfactory and was almost comparable between the groups $(\mathrm{p}=0.339)$. However, knowledge about use of ipratropium inhaler and steroid inhaler was not satisfactory (around $55 \%$ of the patients were informed about these drugs) (Table IV). 
Table IV: Knowledge about medications used for COPD between groups

\begin{tabular}{lccc}
\hline Medication used for COPD & \multicolumn{2}{c}{ Study subjects } & p-value \\
& Group-A & Group-A & \\
& $(\mathbf{n}=\mathbf{7 2})$ & $(\mathbf{n}=\mathbf{7 2})$ & \\
\hline Salbutamol* $^{*}$ & $70(97.2)$ & $72(100.0)$ & 0.248 \\
Ipratropium inhale $^{\#}$ & $36(50.0)$ & $44(61.1)$ & 0.180 \\
Steroid inhale $^{\#}$ & $34(47.2)$ & $43(59.7)$ & 0.131 \\
Aminophyline tabs $^{\#}$ & $59(81.9)$ & $55(76.4)$ & 0.412 \\
\hline Figures in the parentheses denote corresponding percentage & \\
* Fisher's Exact Test was employed to analyze the data & \\
\# Chi Square $\left(\chi^{2}\right)$ Test was employed to analyze the data
\end{tabular}

\section{Management of COPD}

There was no significant difference between patients of Group-A and Group-B with respect to knowledge about management of acute exacerbation of COPD. Around $50 \%$ of the patients in either group knew that nebulizer, spacer and oxygen cylinder were used in management of acute exacerbation COPD. However, knowledge about use of oxygen cylinder was somewhat low among the respondents of Group-A and group-B (37.5 vs. $45.8 \%, \mathrm{p}=0.310)$ (Table V).

Table V: Comparison of Knowledge about management of COPD between groups

\begin{tabular}{lccc}
\hline $\begin{array}{l}\text { Management of acute } \\
\text { exacerbation COPD }\end{array}$ & \multicolumn{2}{c}{ Study subjects } & p-value \\
& $\begin{array}{c}\text { Group-A } \\
(\mathbf{n = 7 2})\end{array}$ & $\begin{array}{c}\text { Group-A } \\
(\mathbf{n}=\mathbf{7 2})\end{array}$ & \\
\hline Nebulizer & $35(48.6)$ & $43(59.7)$ & 0.181 \\
Spacer & $34(47.2)$ & $36(50.0)$ & 0.739 \\
Inhaler & $40(55.6)$ & $35(48.6)$ & 0.404 \\
Oxygen cylinder & $27(37.5)$ & $33(45.8)$ & 0.310 \\
\hline
\end{tabular}

Figures in the parentheses denote corresponding percentage

Chi Square $\left(\chi^{2}\right)$ Test was employed to analyze the data

\section{Opinion of respondents about COPD}

Opinion was sought from the respondents about certain pertinent aspects of COPD which include physical/breathing exercise accentuates respiratory effort, severe breathlessness and increased cough and sputum needs doctor's consultation and fresh air at home decreases the chance of sudden worsening of COPD. All the respondents of either group were in favor of the statements.

Treatment practiced by patients at home before education

Investigating about treatment practiced by. the patients at home revealed that majority $(98.6 \%)$ of Group-B had a significantly poor practice (no consultation with doctors) compared to the patients of Group-A (56.9\%). Over one-quarter $(27.8 \%)$ of the patients of Group-A had at least one consultation as opposed to $1.4 \%$ of Group-B. While $15.3 \%$ of Group-A had 2-3 consultations per month, none of the Group-B had 2-3 consultations.

The difference between the groups in terms of number of check-up was significantly different between the groups $(\mathrm{p}<0.001)$ (Table VI).

Table VI: Treatment practiced by the patients at home between groups

\begin{tabular}{lccc}
\hline $\begin{array}{l}\text { Number of check-up } \\
\text { per month }\end{array}$ & \multicolumn{2}{c}{ Study subjects } & p-Value \\
Group-A & (n=72) & $\begin{array}{c}\text { Group-B } \\
(\mathbf{n}=\mathbf{7 2})\end{array}$ & \\
\hline 0 & $41(56.9)$ & $71(98.6)$ & $<0.001$ \\
1 & $20(27.8)$ & $1(1.4)$ & \\
$2-3$ & $11(15.3)$ & $0(0.0)$ & \\
\hline \multicolumn{4}{l}{ Figures in the parenthesis denote corresponding percentage } \\
Chi Square $\left(\chi^{2}\right)$ Test was employed to analyze the data
\end{tabular}

Treatment practiced by patients at home before education

Table VII demonstrates that $61.1 \%$ of Group-A and $63.9 \%$ of Group-B usednebulizer or spacer or inhaler during acute exacerbation of COPD ( $p=$ 0.731 ), but none used oxygen. Majority of the patients of both groups received antibiotics (95\%) during the attack $(\mathrm{p}=0.500)$.

Table VII: Treatment practiced by the patients at home between groups

\begin{tabular}{lccc}
\hline $\begin{array}{l}\text { Home management by the } \\
\text { patients }\end{array}$ & \multicolumn{2}{c}{ Study subjects } & p-Value \\
& $\begin{array}{c}\text { Group-A } \\
(\mathbf{n}=\mathbf{7 2})\end{array}$ & $\begin{array}{c}\text { Group-B } \\
(\mathbf{n}=\mathbf{7 2})\end{array}$ & \\
\hline Use of nebulizer/ spacer/inhaler & $44(61.1)$ & $46(63.9)$ & 0.731 \\
Use of oxygen & $0(0.0)$ & $0(0.0)$ & - \\
Use of antibiotics & $68(94.4)$ & $69(95.5)$ & 0.500 \\
\hline Figures in the parenthesis denote corresponding percentage & \\
Chi Square $\left(\chi^{2}\right)$ Test was employed to analyse the data &
\end{tabular}

\section{Health service used during hospital stay}

Outcome of structured education to COPD patients was evaluated one year after educations. The evaluation findings show that $30.6 \%$ of the patients who received education (Group-A) did not require any hospital admission during the period, 58.3\% required only one admission and 
only $11.1 \%$ needed 2 or more admissions. In contrast, all the patients of COPD (Group-B) who did not receive education required 2 or more admissi6ns during the same period. The difference is highly significant $(\mathrm{p}<0.001)$. The average duration of hospital stay was also significantly less in Group-A than that in the Group-B (2.0 \pm 0.3 vs. $3.0 \pm 0.6$ days, $\mathrm{p}<0.001)$. However, number of physician consultations $(>2)$ was much higher in the former group $(26.4 \%)$ than that in the latter group $(6.9 \%)(p=0.002)$ (Table VIII)

Table VIII: Comparison of health service used during hospital stay between groups

\begin{tabular}{lccc}
\hline $\begin{array}{l}\text { Health Service used } \\
\text { during hospital stay }\end{array}$ & \multicolumn{2}{c}{ Study subjects } & p-Value \\
& $\begin{array}{c}\text { Group-A } \\
\text { (n=72) }\end{array}$ & $\begin{array}{c}\text { Group-B } \\
\text { (n=72) }\end{array}$ & \\
\hline Number of hospital admission * & & & \\
$\quad$ No admission & $22(30.6)$ & $0(0.0)$ & \\
$\quad$ One admission & $42(58.3)$ & $0(0.0)$ & $<0.001$ \\
$>2$ admission & $8(11.1)$ & $72(100.0)$ & \\
$\quad$ Average duration of hospital stay & $2.0 \pm 0.3$ & $3.0 \pm 0.6$ & $<0.001$ \\
Number of physician consultations* & & & \\
$\leq 2$ & $53(73.6)$ & $67(93.1)$ & 0.002 \\
$>2$ & $19(26.4)$ & $5(6.9)$ & \\
\hline * Chi square $\left(\chi^{2}\right)$ Test was employed to analyze the data & &
\end{tabular}

\section{Status of exacerbation}

The patients of Group-A had mild and moderate exacerbation (44\% and 52.8\%). Very few had severe exacerbation. In contrast, majority of (94.4\%) of Group-B had severe exacerbation. The difference was statistically significant $(\mathrm{p}<0.001)$

(Fig. 2)

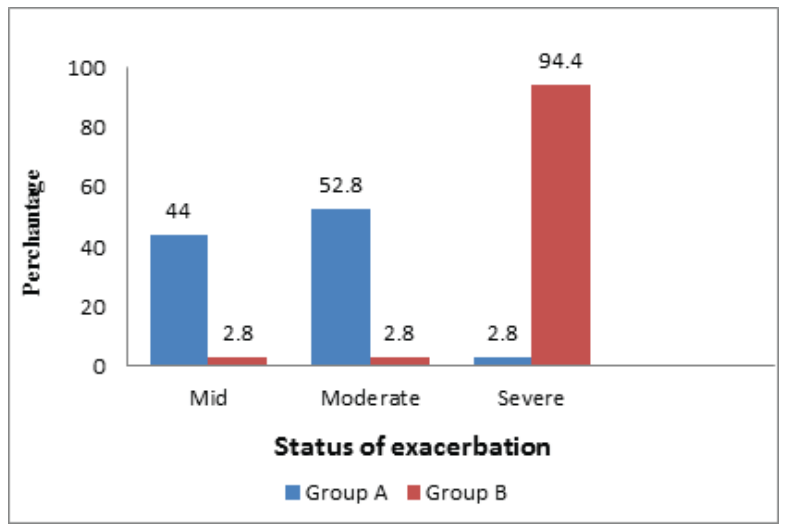

Fig. 2: Status of acute exacerbation of patients following education

\section{Practice status of patients following education}

The COPD patients who received education had an appreciably higher use of inhaler at home than their comparators without structured education ( $\mathrm{p}$ $<0.001$ ). Similarly home antibiotic use and steroid use were significantly higher in Group-A than those in Group-B ( $p=0.023$ and $p<0.001$ respectively) The physical and breathing exercises, use of mask in dusty or smoky places, diet as instructed by the physicians and use of rescue salbutamol/ipratropium nebulisation during an attack were only practiced by patients who received structured education (Table IX).

Table IX: Practice status of patients following education

\begin{tabular}{|c|c|c|c|}
\hline \multirow[t]{2}{*}{ Practice status of patients } & \multicolumn{2}{|c|}{ Study subjects } & \multirow[t]{2}{*}{ p-Value } \\
\hline & $\begin{array}{c}\text { Group-A } \\
(\mathrm{n}=72)\end{array}$ & $\begin{array}{c}\text { Group-B } \\
(\mathrm{n}=72)\end{array}$ & \\
\hline Use of inhaler at home & $71(91.6)$ & $3(4.2)$ & $<0.001$ \\
\hline Home antibiotic use & $72(100.0)$ & $67(93.1)$ & 0.023 \\
\hline Steroid use at home & $55(76.4)$ & $19(26.4)$ & $<0.001$ \\
\hline Physical/breathing exercise & $72(100.0)$ & - & $<0.001$ \\
\hline Use of mask in smoky and dusty places & $70(92.2)$ & - & $<0.001$ \\
\hline Complied to the diet instructed by physician & $72(100.0)$ & - & $<0.001$ \\
\hline Use of rescue salbutamol/ipratropium nebulisation & $30(41.7)$ & - & $<0.001$ \\
\hline
\end{tabular}

\section{Status of smoking following education}

Number of current smokers in the present study was 55. Of them 30 were in Group-A and 25 in Group-B. Of the 30 smokers, 29(96.7\%) quitted smoking following structured education and $1(3.3 \%)$ reduced the frequency of smoking. Sharply contrasting to these findings, none of the 25 smokers of Group-B gave up smoking. One (4\%) reduced the frequency and 24(96\%) continued smoking as before. The groups were significantly heterogeneous in terms of smoking status following structured education $(\mathrm{p}<0.001)$ (Table X)

Table X: Comparison of status of smoking following education

\begin{tabular}{lccc}
\hline Smoking status & \multicolumn{2}{c}{ Study subjects } & p-Value \\
& $\begin{array}{c}\text { Group-A } \\
(\mathbf{n}=\mathbf{3 0})\end{array}$ & $\begin{array}{c}\text { Group-B } \\
(\mathbf{n}=\mathbf{2 5}\end{array}$ & \\
\hline As before & $0(0.0)$ & $24(96.0)$ & \\
Reduced & $1(3.3)$ & $1(4.0)$ & $<0.001$ \\
Quitted & $29(96.7)$ & $0(0.0)$ & \\
\hline
\end{tabular}

Figures in the parentheses denote corresponding percentage

* Chi Square $\left(\chi^{2}\right)$ Test was employed to analyze the data

\section{Discussion}

Chronic obstructive pulmonary disease consumes a considerable amount of health care resources 
due to frequent hospitalization. Despite optimal pharmacologic therapy, patients with COPD often have symptoms severe enough to limit normal physical activities of daily living and affect quality of life. ${ }^{3}$ It necessitates a major part of patient care to impose on patients' themselves. The present study was carried out to see the impact of structured training (self-management training) on reduction of acute exacerbation and hospitalization rates over a period of one year follow-up in patients with COPD. The present study is, by far, the first such study in Bangladesh.

In the present trial, majority of the patients was elderly ( 60 or $>60$ years old), male, rural residents and uneducated. in a similar study conducted in Canada reported that most patients were elderly, not highly educated and had advanced COPD. Males were somewhat higher than the females in frequency. ${ }^{23}$ These findings are almost consistent with the findings of the present study. The prevalence of COPD increases with age, with a five-fold increased risk for those aged over $65 \mathrm{yrs}$ compared with patients aged less than $40 \mathrm{yrs}^{24}$

The prevalence increases with smoking status, but it needs to be emphasized that prevalence of COPD in nonsmokers was $4 \%$, suggesting the existence of other risk factors, such as passive smoking, or factors of occupational exposure. COPD affects twice as many males as females. But this difference will diminish, given the fact that more and more females throughout the world have taken up smoking in the past few years in developed countries, and that nonsmoking females are exposed to biomass combustion products in developing countries. ${ }^{25}$

There are geographical disparities, with a higher prevalence of COPD in South-East Asia (12.5\%), but it should be noted that there is an absence of data available concerning a large part of the world (the African continent and countries around the Mediterranean), for the majority of studies are concerned with Europe. The prevalence of moderate to severe COPD was modeled in 12 South-East Asian countries and estimated to be
$6.3 \%$, with maximum prevalence in China (6.5\%) and in Vietnam (6.7\%). ${ }^{26}$ In South America, the PLATINO study enabled the prevalence of COPD in those aged over 40 years to be estimated at between $7.8 \%$ and $20 \%{ }^{27}$

The two study groups in the present study were similar with respect to pertinent demographic characteristics like age, sex, educational status. The smoking status of the subjects (like present or past smoker), number of sticks smoked per day and duration of smoking were almost identical between groups. Knowledge about different aspects of COPD, medications used during acute exacerbation of COPD were fairly comparable between groups before intervention. Management given during hospital stay was also no different between the groups.

The evaluation revealed that over $30 \%$ of the patients who received structured training did not need any hospital admission during the period, $58.3 \%$ needed only one admission and $11.1 \%$ needed 2 or more admissions, while all the patients who were given standard care alone required two or more admissions during the same period $(\mathrm{p}<0.001)$. Besides, the duration of hospital stay was on an average 1 day less in the former group than that in the latter group $(2.0 \pm$ 0.3 vs. $3.0 \pm 0.6$ days, $\mathrm{p}<0.001)$. Meanwhile the number of consultations ( $>2$ during the period of 1 year) with their physicians significantly higher in the former group $(26.4 \%)$ than that in the latter group $(6.9 \%)(p=0.002)$ indicating that the patient who received structured training became more conscious about consultation with their physicians at the earliest of the disease exacerbation before it turned into sever form. The result of higher number of consultations by the patients who received education is reflected in the severity of exacerbation with majority having mild or moderate attack, while the patients who received standard care but no education made fewer visits with physicians and about $95 \%$ of them had severe form acute exacerbation. 
The subjects who received education demonstrated significantly higher use of inhaler at home than their counterparts without education ( $p$ $<0.001)$. Likewise home use of antibiotics and steroid use were considerably higher in the former group than that in latter group $(\mathrm{p}=0.023$ and $\mathrm{p}<$ 0.001 respectively). The physical and/or breathing exercises, use of mask while in dusty or smoky places, compliance to recommended diet and use of rescue salbutamol or ipratropium inhaler and nebulisation during an attack were only practiced by the patients who received structured education indicating that the role of structured training in motivating patients of COPD for adopting supportive management is also pervasive. As all the pertinent baseline characteristics of the two groups of patients were similar, the treatment effects cannot be explained by differences in subjects' baseline characteristics. Therefore, the differences in outcome between the groups can solely be attributed to intervention (structured training). ${ }^{28}$ In a multicentre, randomised clinical trial on 191 COPD patients from seven provincial hospitals of Canada showed almost similar results as we found in our study. Patients in both groups had similar sociodemographic and clinical characteristics with majority being elderly, smokers or ex-smokers and not highly educated. Disease severity was also similar according to FEV1, dyspnoea and exercise capacity. One group received self-management education and other did not. The evaluation result showed that the self-management group had a significantly higher reduction in the rate of hospitalizations in the $1 \mathrm{st}$ year of the study as compared to the year preceding enrolment, while the standard-care group experienced a slight increase in hospitalizations during the same period of time. The emergency room visit was also significantly reduced in the former group as compared to slight increase in the latter group. ${ }^{23}$ In a small randomized trial of early pulmonary rehabilitation after hospitalization for acute exacerbation, ${ }^{29}$ reported a significant reduction in emergency department visits and a trend toward reduced numbers of hospital admissions and days spent in the hospital over the
3 months after hospital discharge in the pulmonary rehabilitation group compared to the usual-care group. Also, in a multicenter randomized trial of a self-management program of patients with severe COPD, ${ }^{23}$ reported a significant reduction in thenumbers of hospital admissions and days spent in the hospital in the year following the intervention compared to the usual-care control group. The result showed that hospital admissions for exacerbation of COPD were reduced by $39.8 \%$ in the intervention group compared with the usual care group and admissions for other health problems were reduced by $57.1 \%$. Emergency department visits were reduced by $41 \%$ which also bears consistency with the present study. Different studies have shown that nearly half of patients with COPD discharged from hospitals are readmitted during the following year, ${ }^{9,30}$ and $17 \%$ of patients discharged from emergency departments require hospitalization. ${ }^{31}$

Overall our study showed that patients with COPD who received an structured training, based on the concept of pulmonary rehabilitation, ${ }^{32}$ had a better outcome than the usual care group with respect to frequency of hospital admissions, severity of attack, stay in the hospital and smoke cessation. These differences, especially those on health care utilization, are important and worth considering. The health benefits gained by the patients through self-management could potentially add to the patients' quality of life by avoiding hospitalization. Although we cannot identify which component of the intervention had an effect, the effective outcome nevertheless remain important, considering the heavy burden of the disease on our limited health resources.

From the findings of the study it can be concluded that the patients with COPD who received a structured training in addition to usual care require significantly less hospitalization and had less severe exacerbations in the subsequent year as compared to their counterparts who received only usual care and no educational intervention. COPD causes an enormous health burden in developing countries like ours and it is difficult to combat this menace with limited health resources. However, educating the patients with structured training and 
shouldering the responsibility of patient-care to patients themselves will go a long way in reducing the burden of acute exacerbation of COPD in our country which will save a considerable amount of health care resources.

\section{Recommendations}

In the light of the findings of the study and discussion thereof, the following recommendations are laid down:

1. As structured training to COPD patients has demonstrated effect in reducing the recurrent attacks and re-hospitalization, these training should be implemented at all levels of health care setting where applicable and scope prevails.

2. Patients should be made aware about all potential risk factors of COPD and also about the means of protecting themselves from those risk factors.

3. As the studies that followed up the patients for 2 years showed a decrease in knowledge and practice of the patients in the 2nd year than those in the 1St year, Refreshers training seems essential to keep the effect of training for longer duration.

4. Further study on structured training of COPD should include vaccination against influenza and pneumococcal infection to see their effect on reducing the incidence of recurrent exacerbation and readmission due to COPD.

\section{Acknowledgement}

All thanks be to Almighty Allah, the Most Merciful, the Most Beneficent that by His endless grace I have been able to complete this study in time. I am thankful to Prof. M.A. Azhar, MBBS, FCPS, FACP, Professor \& Head Department of Medicine, Prof. Dilip Kumar Dhar, Department of Medicine, Prof. Anup Kumar Saha, Dept. of Medicine \& Dr. Asif Mustafa, Associate Professor, Department of Pulmonolgy, SSMC \& Mitford Hospital Dhaka, for their constant supervision, inspiring guidance \& encouragement to my study. I must express gratefulness to all Asst. Registrar, Registrar, IMO, HMO, intern doctors, whose sincere co-operation made this study possible.

\section{References}

1. Reid PT, Innes JA. Respiratory Disease. In: Colledge NR, Walker BR, Ralston SH, editors. Davidson's Principles and Practice of Medicine. 21st ed. London: Elsevier Ltd; 2010. p. 671.

2. World Health Organization [Internet]. Geneva, Switzerland: The World Health Report 2004 [cited 2010 Jan 14]. Available from: http://www.who.int/whr/2004/en/.

3. Murray CJ, Lopez AD. Alternative Projections of Mortality and Disability by Cause 1990-2020: Global Burden of Disease Study. Lancet. 1997;349:1498-1504.

4. Pauwels RA, Buist AS, Calverley PM, Jenkins CR, Hurd SS; GOLD Scientific Committee. Global Strategy for the Diagnosis, Management, and Prevention of Chronic Obstructive Pulmonary Disease: NHLBI/WHO Global Initiative for Chronic Obstructive Lung Disease (GOLD) Workshop Summary. Am J Respir Crit Care Med. 2001;163(5 Pt 1):1256-76.

5. Regueiro CR, Hamel MB, Davis RB, Desbiens N, Connors AF Jr, Phillips RS. A Comparison of Generalist and Pulmonologist Care for Patients Hospitalized with Severe Chronic Obstructive Pulmonary Disease: Resource Intensity, Hospital Costs, and Survival: Study to Understand Prognoses and Preferences for Outcomes and Risks of Treatment. Am J Med. 1998;105(5):366-72.

6. Seemungal TAR, Donaldson GC, Paul EA, Bestall JC, Jeffries DJ, Wedzicha JA. Effect of Exacerbation on Quality of Life in Patients with Chronic Obstructive Pulmonary Disease. Am J Respir Crit Care Med. 1998;157(5):1418-22.

7. Mandell LA, Wunderink RG, Anzueto A, Bartlett JG, Campbell GD, Dean NC, et al. Infectious Diseases Society of America; American Thoracic Society Infectious Diseases Society of America/American Thoracic Society Consensus Guidelines on the Management of Community Acquired Pneumonia in Adults. Clin Infect Dis. 2007:27-72.

8. Mannino DM. COPD: Epidemiology, Prevalence, Morbidity and Mortality, and Disease Heterogeneity. Chest. 2002;121(5 Suppl):S121-26. 
9. Connors AF Jr, Dawson NV, Thomas C, Harrell FE Jr, Desbiens N, Fulkerson WJ, et al. Outcomes Following Acute Exacerbation of Severe Chronic Obstructive Lung Disease. Am J Respir Crit Care Med. 1996;154(4 Pt 1):959-67.

10. Seneff MG, Wagner DP, Wagner RP, Zimmerman JE, Knaus WA. Hospital and 1-Year Survival of Patients Admitted to Intensive Care Units with Acute Exacerbation of Chronic Obstructive Pulmonary Disease. JAMA. 1995;274:1852-57.

11. Sullivan SD, Ramsey SD, Lee TA. The Economic Burden of COPD. Chest. 2000;117(2 Suppl):S5-9.

12. Qureshi H, Sharafkhaneh A, Hanania NA. Chronic Obstructive Pulmonary Disease Exacerbations: Latest Evidence and Clinical Implications. Ther Adv Chronic Dis. 2014 Sep; 5(5): 212-27.

13. Garcia-Aymerich J, Farrero E, Felez MA, Izquierdo J, Marrades RM, Anto JM. Risk Factors of Readmission to Hospital for a COPD Exacerbation: A Prospective Study. Thorax. 2003;58:100-105.

14. Snow V, Lascher S, Mottur-Pilson C. Evidence Base for Management of Acute Exacerbations of Chronic Obstructive Pulmonary Disease. Ann Intern Med. 2001;134(7):595-99.

15. Lacasse Y, Brosseau L, Milne S, Martin S, Wong E, Guyatt GH, et al. Pulmonary Rehabilitation for Chronic Obstructive Pulmonary Disease. Cochrane Database Syst Rev. 2002;3:CD003793.

16. Spruit MA, Gosselink R, Troosters T, Kasran A, Gayan-Ramirez G, Bogaerts P, et al. Muscle Force during an Acute Exacerbation in Enitorized Patients with COPD and its Relationship with CXCL8 and IGF-1. Thorax. 2003;58:752-56.

17. Decramer M, Gosselink R, Troosters T, Verschueren M, Evers G. Muscle Weakness Is Related to Utilization of Health Care Resources in COPD Patients. Eur Respir J. 1997;10:417-23.

18. Celli BR, Cote CG, Marin JM, Casanova C, Montes 0 , Mendez RA, et al. The Body-Mass Index, Airflow Obstruction, Dyspnea, and Exercise Capacity Index in Chronic Obstructive Pulmonary Disease. N Engl J Med. 2004;350:1005-12.

19. Troosters T, Casaburi R, Gosselink R, Decramer M. Pulmonary Rehabilitation in Chronic Obstructive Pulmonary Disease. Am J Respir Crit Care Med. 2005;172(1):29-38.
20. Gibson PG, Powell H, Coughlan J, Wilson AJ, Abramson M, Haywood P, et al. Self-management Education and Regular Practitioner Review for Adults with Asthma. Cochrane Database Syst Rev. 2003;1:CD001117.

21. Gibson PG, Ram FSF, Powell H. Asthma Education. Respiratory Medicine. 2003;97(9):1036-44

22. Bangladesh Lung Heath Manual. Bangladesh Lung Foundation. 2009;1:97.

23. Bourbeau J, Julien M, Maltais F. Reduction of Hospital Utilization in Patients with Chronic Obstructive Pulmonary Disease: A Disease-Specific Self-Management Intervention. Arch Intern Med. 2003;163:585-91

24. Antó JM, Vermeire $P$, Vestbo J, Sunyer J. Epidemiology of Chronic Obstructive Pulmonary Disease. Eur Respir J. 2001;17(5):982-94.

25. Raherison C, Girodet PO. Epidemiology of COPD. Eur Respir Rev. 2009;18(114):213-21.

26. Chan-Yeung M, Ait-Khaled N, White N, Ip MS, Tan WC. The burden and impact of COPD in Asia and Africa. Int J Tuberc Lung Dis 2004; 8: 2-14.

27. Menezes AM, Perez-Padilla R, Jardim JR, Muiño A, Lopez MV, Valdivia G, et al. Chronic Obstructive Pulmonary Disease in Five Latin American Cities (The PLATINO Study): A Prevalence Study. Lancet 2005;366(9500):1875-81.

28. Gompertz S, O'Brien C, Bayley DL, Hill SL, Stockley RA. Changes in Bronchial Inflammation during Acute Exacerbations of Chronic Bronchitis. Eur Respir J. 2001;17:1112-19.

29. Man WDC, Polkey MI, Donaldson N. Community Pulmonary Rehabilitation after Hospitalisation for Acute Exacerbations of Chronic Obstructive Pulmonary Disease: Randomized Controlled Study. BMJ. 2004;329:1209-13.

30. Osman IM, Godden DJ, Friend JA, Legge JS, Douglas JG. Quality of Life and Hospital Readmission in Patients with Chronic Obstructive Pulmonary Disease. Thorax. 1991;52:67-71.

31. Emerman CL, Efrron D, Lukens TW. Spirometric Criteria for Hospital Admission of Patients with Acute Exacerbation of COPD. Chest. 1991;99:595-99.

32. Ras G, Wilson R, Todd H, Taylor G, Cole P. The Effect of Bacterial Products on Neutrophil Migration in Vitro. Thorax. 1990;145:276-80. 